\title{
Avaliação do protocolo PCR4 de Marchetti em tecidos parafinizados para o diagnóstico da tuberculose cutânea e ganglionar
}

\author{
Evaluation of Marchetti PCR4 amplification assay to the diagnosis of cutaneous and lymph node tuberculosis \\ from formalin-fixed paraffin-embedded tissue
}

Luciana Botinelly Mendonça Fujimoto'; Júlia Ignez Salem²; Maurício Morishi Ogusku³; Luiz Carlos de Lima Ferreira ${ }^{4}$

\begin{abstract}
unitermos
Tuberculose cutânea

Material parafinizado

Mycobacterium tuberculosis

PCR

IS6110

\section{resumo}

Introdução: A tuberculose cutaneoganglionar (TbCG) corresponde a 25,4\% dos casos de tuberculose (Tb) extrapulmonar no estado do Amazonas. Os métodos tradicionais, bacteriológicos e histopatológicos envolvem algumas dificuldades diagnósticas, e a reação em cadeia da polimerase (PCR) surge como método alternativo, podendo propiciar resultados específicos e em menor tempo. Nesse sentido, verificou-se a acurácia do protocolo PCR4 de Marchetti et al. no diagnóstico da TbCG comparativamente aos métodos bacteriológicos e histopatológicos. Materiais e métodos: Realizou-se o nested-PCR com oligonucleotídeos para a IS6110 do complexo do M. tuberculosis em 83 amostras parafinizadas, sendo 52 cutâneas e 31 ganglionares, de pacientes clinicamente suspeitos de TbCG. Todos os casos foram avaliados pelos métodos bacteriológicos e histopatológicos. Foi realizada análise da acurácia entre os resultados obtidos na PCR em relação ao cultivo e à histopatologia. Resultados e discussão: A positividade da PCR em todos os casos estudados foi de 50,6\% (42/83), sendo de 59,6\% (31/52) em amostras cutâneas e de $35,5 \%(11 / 31)$ nas ganglionares. Em ambos os grupos foram observados resultados falso-positivos e falso-negativos. Algumas hipóteses que podem justificar estes resultados estão relacionadas à presença da IS6110 em micobactérias ambientais da região amazônica e à não-padronização da amostra de DNA amplificado. Conclusão: O protocolo em avaliação apresentou positividade em percentual semelhante a diferentes protocolos existentes na literatura. Sugere-se o uso da PCR em tecidos parafinizados associada com o cultivo ou com a histopatologia para o diagnóstico definitivo de Tb ganglionar. Para as lesões cutâneas continua sendo necessária a busca de protocolo que amplie a acurácia do método.
\end{abstract}

Background: Cutaneous lymph node tuberculosis (CLTb) represents 25.4\% of all cases of extra-pulmonary Tb in the state of Amazonas. The current methods of diagnose including bacteriological and histopathological assays involve some technical difficulties, and the polymerase chain reaction - PCR arise as an alternative method allowing specific results faster than the others. In this context the accuracy of PCR4 Marchetti et al. protocol was compared with traditional methods. Material e method: Nested-PCR for IS6110 (123 pb) were applied on 83 CLTb suspicious formalin fixed and paraffin embedded samples of tissues (52 cutaneous and 31 lymph node), obtained from 1997 to 2002. All cases were evaluated by bacteriological and histopathological methods. Accuracy analyses were carried out between the PCR amplification results and those related on bacteriological and histopathological methods. Results and Discussions: Positive results of PCR 4 were about $50.6 \%$ (59.6\% in cutaneous samples and of $35.5 \%$ in lymph nodes samples). In both groups were observed false-negative and false-positive results. Some hypotheses that explain those results are related to the presence of IS6110 in environmental mycobacterias in the Amazon region and the absence of standardized DNA concentration to amplification assays. Conclusions: The proposed protocol was as positive as others ones available in the literature. Definitive Tb diagnostic can be obtained on lymph node paraffin embedded PCR in association with bacteriological or histopathological method. A better accuracy of an amplification assay applied to cutaneous Tb suspicious lesions has to be still under research.

\section{key words}

Cutaneous tuberculosis

formalin-fixed and paraffin-

embedded tissues

Mycobacterium tuberculosis

$P C R$

IS6110

\footnotetext{
1. Médica; patologista; mestra; professora-assistente do Departamento de Patologia e Medicina Legal da Universidade Federal do Amazonas (UFAM).

2. Médica; microbiologista; doutora; pesquisadora titular e chefe do Laboratório de Micobacteriologia do Instituto Nacional de Pesquisas da Amazônia (INPA).

3. Farmacêutico-bioquímico; mestre; pesquisador do Laboratório de Micobacteriologia do INPA.

4. Médico; patologista; doutor; professor-adiunto do Departamento de Patologia e Medicina Legal da UFAM.

Trabalho realizado no Laboratório de Micobacteriologia do INPA e no Laboratório de Patologia da UFAM. Parte da dissertação (mestrado em Patologia Tropical da UFAM) da primeira autora, defendida em 30 de setembro de 2004 e orientada pelos segundo e quarto autores.

Apoio Financeiro: Fundação de Amparo à Pesquisa do Estado do Amazonas (FAPEAM) e Programa Norte de Pesquisa e Pós-Graduação, Rede Norte de Pesquisa e Pós-Graduação, Fundação Coorde-
} nação de Aperfeiçoamento de Pessoal de Nível Superior (PNOPG/RENOR/CAPES). 


\section{Introdução}

Para o diagnóstico da tuberculose cutaneoganglionar (TbCG) são utilizados métodos de isolamento do agente (padrão-ouro) e/ou o exame histopatológico para evidenciar padrões histopatológicos indicativos de tuberculose (Tb), como granulomas e presença de bacilo álcool-ácidoresistente (BAAR). O primeiro é dependente do número de BAAR e requer em torno de 30 dias para o diagnóstico. $O$ segundo não é patognomônico de Tb e a presença de BAAR não corresponde obrigatoriamente a espécies do complexo Mycobacterium tuberculosis. Entretanto, a aliança entre métodos moleculares e histopatológicos tem se mostrado promissora em contornar as dificuldades de diagnóstico específico em curto período de tempo e sem a obrigatoriedade de isolamento da cepa agressora. Nesse sentido, estudos com a reação em cadeia da polimerase (PCR) vêm sendo realizados para identificação do microrganismo nos tecidos parafinizados, principalmente com a utilização de oligonucleotídeos que amplifiquem segmentos complementares à seqüência de inserção IS6110, considerada específica para o complexo M. tuberculosis $(1,5,7,13,14,16,22,25,27,29)$. Entre os referidos estudos se destaca o realizado por Marchetti et al. ${ }^{(14)}$, que, utilizando um protocolo denominado PCR4, obteve as melhores taxas de positividade em amostras com suspeita ou confirmação clínica de Tb, infiltrado inflamatório crônico granulomatoso (lesão necrotizante) com BAAR e cultivo positivo ou não para M. tuberculosis.

Os resultados de Marchetti et al.(14) podem ser promissores para o estado do Amazonas, pois no período de 1997 a 2002 foram notificados 402 casos novos de Tb com localização cutânea e/ou ganglionar ${ }^{(26)}$. Em apenas 32 (8\%) o diagnóstico foi estabelecido pelo isolamento in vitro do M. tuberculosis. Conseqüentemente, $92 \%$ foram notificados devido a suspeita clínica e/ou indicação histopatológica da presença de granulomas nos fragmentos dos tecidos lesados, propiciando que a notificação da maior parte dos casos foi determinada como diagnóstico presuntivo. Pelo exposto, são necessários estudos que gerem conhecimentos sobre a parceria entre ferramentas moleculares e técnicas histopatológicas tradicionais para o diagnóstico de lesões cutâneas e/ou ganglionares com suspeita de tuberculose.

Assim, o presente trabalho verificou a acurácia do protocolo PCR4 de Marchetti et al.(14) para o diagnóstico da TbCG comparativamente aos métodos bacteriológicos e histopatológicos. Entretanto, visando seu uso em unidades da rede básica de diagnóstico laboratorial, não se realizou a etapa de padronização da concentração do DNA extraí- do em 1 e $3 \mu \mathrm{g}$, conforme recomendado por Marchetti et al. ${ }^{(14)}$ para o protocolo PCR4, devido à necessidade de equipamentos e insumos pouco acessíveis nos serviços básicos de saúde.

\section{Materiais e métodos}

\section{Amostras clínicas}

De 174 amostras de tecidos recebidas no período de 1997 a 2002 no Laboratório de Micobacteriologia do Instituto Nacional de Pesquisas da Amazônia (INPA) para diagnóstico de tuberculose, 52 de lesões cutâneas e 31 de gânglios foram selecionadas para o presente estudo mediante os seguintes critérios de inclusão: suspeita clínica de tuberculose ou micobacteriose cutaneoganglionar, existência de resultados bacteriológicos com cultivo negativo ou positivo para micobactérias, presença de correspondente amostra fixada em formol e parafinizada em quantidade representativa para reavaliação histopatológica e realização da PCR. Cada uma das amostras parafinizadas já havia sido processada e avaliada nos serviços de patologia da Fundação Alfredo da Matta (FUAM), da Fundação de Medicina Tropical (FMT) ou do Departamento de Patologia e Medicina Legal da Universidade Federal do Amazonas (DPML/UFAM). Quando disponíveis, informações clinicoepidemiológicas relevantes à pesquisa foram analisadas em conjunto com os resultados obtidos.

O presente estudo foi aprovado pelos Comitês de Ética em Pesquisa com Seres Humanos da FUAM, processo 0224/03, e da FMT, processo 1038/2003.

\section{Exames bacteriológicos}

Realizados no mesmo dia de coleta do fragmento, abrangeram a execução de baciloscopia direta e pósconcentração e de cultivo em meio de Löwenstein-Jensen, conforme estabelecido por Salem et al.(21). Os cultivos sem crescimento micobacteriano foram considerados negativos após o período de dois meses e os positivos para BAAR foram submetidos aos testes de velocidade de crescimento e produção de pigmentos. Todas as cepas não-cromogênicas e de crescimento lento que nas provas bioquímicas produziram niacina e reduziram fortemente o nitrato a nitrito foram identificadas como cepas de $M$. tuberculosis, conforme proposto por David et al. ${ }^{(6)}$. As demais foram consideradas micobactérias não-tuberculosas (MNT). 


\section{Exame histopatológico}

Cortes de $4 \mu \mathrm{m}$ foram corados pelos métodos de hematoxilina-eosina (HE) ${ }^{(2)}$ e de Wade ${ }^{(28)}$ e analisados quanto à presença dos indicativos de TbCG, isto é, infiltrado inflamatório crônico granulomatoso (IICG), associado ou não a células gigantes multinucleadas do tipo Langerhans, necrose caseosa e/ou BAAR.

\section{PCR}

Todas as etapas foram realizadas conforme o protocolo PCR4 de Marchetti et al. ${ }^{(14)}$, inclusive os oligonucleotídeos para amplificação da seqüência de inserção IS6110 e para controle de integridade do DNA das amostras extraídas.

Como medidas de controle de contaminação cruzada entre os cortes dos tecidos parafinizados utilizaram-se navalhas descartáveis novas para cada amostra. O micrótomo foi rotineiramente limpo com xilol e álcool absoluto e realizou-se a PCR em cortes de blocos contendo apenas parafina. Esses foram inseridos a cada cinco blocos de tecidos parafinizados, etapa não prevista no trabalho de Marchetti et al.(14). Também foram introduzidos controles de contaminação de todos os reagentes e materiais descartáveis utilizados. Em cada sessão de PCR foi incorporado um controle positivo contendo DNA de M. tuberculosis $\mathrm{H}_{37} \mathrm{Rv}$, um controle negativo com água Milli-Q estéril e controles negativo e positivo de extração de DNA.

As amplificações foram realizadas em termociclador GeneAmp ${ }^{\circledast}$ PCR System 2400 (Applied Biosystems). Os produtos amplificados foram submetidos à eletroforese em gel de agarose a $2 \%$ para nested-PCR e a $1,5 \%$ para as demais reações, corados com brometo de etídeo, visualizados em transiluminador de luz ultravioleta e fotodocumentados no sistema Eagle Eye ${ }^{\circledR}$ II (Stratagene).

Todos os procedimentos foram executados em cabine de segurança biológica e cada etapa da PCR foi realizada em diferente ambiente, visando evitar a ocorrência de contaminação.

\section{Análise dos dados}

A interferência dos anos de emblocamento na positividade da PCR foi calculada pelo qui-quadrado $\left(\chi^{2}\right)$ para análise de tendência linear, com $p \leq 0,05$. As falsas positividade e negatividade da PCR, sensibilidade, especificidade e valores preditivos positivo e negativo em relação aos resultados do cultivo e dos parâmetros histopatológicos, conforme origem clínica das lesões, foram calculados a partir de tabelas $2 \times 2$ (programa Epi-Info versão 6.04d, para DOS) ${ }^{(4)}$.
Nas análises da co-positividade e co-negatividade entre os métodos laboratoriais realizados também foram utilizadas tabelas $2 \times 2$.

\section{Resultados}

Todos os controles de contaminação inseridos nas diferentes etapas da PCR apresentaram resultados negativos de complementaridade aos oligonucleotídeos da seqüência de inserção IS6110. Constatou-se que o tempo de emblocamento das amostras não interferiu nos percentuais de positividade da PCR $(p=0,1066)$.

As lesões cutâneas corresponderam a $62,6 \%(52 / 83)$ das amostras estudadas, e as ganglionares, a 37,4\% (31/83). A PCR apresentou positividade em 50,6\% (42/83) de todos os casos estudados, sendo de $59,6 \%$ (31/52) em amostras cutâneas e de 35,5\% (11/31) nas ganglionares. Entretanto, em 12 amostras cutâneas obteve-se isolamento de MNTs, sendo que em oito a PCR foi positiva. Dessas, em quatro foram isoladas mais de cem colônias de MNT por tubo de meio semeado, das quais apenas uma tinha BAAR tecidual e IICG. Das três restantes, apenas duas tinham a presença de IICG e a outra teve um laudo de eczema crônico inespecífico. Aparentemente houve falsa-positividade da PCR nas amostras cutâneas, fato que não ocorreu nas amostras ganglionares.

Os resultados da PCR em relação à presença ou ausência de IICG e de BAAR tecidual e ao cultivo positivo ou negativo para M. tuberculosis, conforme o tipo de amostra analisada, estão apresentados na Tabela 1. Nessa análise os quantitativos de amostras com isolamento de MNT foram considerados cultivos negativos para $M$. tuberculosis. As MNTs em amostras cutâneas e ganglionares com IICG e BAAR positivo corresponderam a 2/13 (15,4\%) e 1/1 (100\%), respectivamente, enquanto com IICG sem BARR obtiveram-se $6 / 20(30,0 \%)$ e $1 / 6(16,6 \%)$; e nas amostras sem IICG e BAAR foram isoladas em $4 / 12$ casos (33,3\%) e $1 / 3(33,3 \%)$. Constata-se que nas amostras cutâneas tem-se uma ampliação de percentuais mediante a ausência dos parâmetros histopatológicos indicativos de Tb (IICG e BAAR). Entre os resultados encontrados é importante ressaltar que, nas amostras com cultivo negativo para $M$. tuberculosis, presença de BAAR tecidual e de IICG, critérios utilizados por Marchetti et al. ${ }^{(14)}$ em uma de suas análises, a PCR somente foi positiva em amostras cutâneas.

Nos dados da Tabela 1 constatam-se resultados falsonegativos da PCR quando ela é analisada em relação apenas ao cultivo positivo para $M$. tuberculosis, que nas amostras 
cutâneas foi de $42,8 \%$ (3/7) e nas ganglionares, $57,1 \%$ (12/21). Resultado semelhante foi obtido na análise entre a PCR e a baciloscopia tecidual, onde a provável falsa-negatividade foi de $35,7 \%$ (5/14) nas amostras cutâneas e $69,2 \%(9 / 13)$ nas ganglionares.

Conforme o tipo de amostra analisada, os resultados de acurácia da PCR em relação a um ou mais métodos diagnósticos tradicionalmente executados estão apresentados na Tabela 2. Constatou-se que a PCR apresentou maior valor de co-positividade nas amostras cutâneas, exceto na análise com o cultivo Mtb/IICG/BAAR tecidual (0\%). Tal fato é confirmado pelo valor preditivo positivo (VPP) encontrado (0\%), pois, de nove amostras com positividade para cultivo Mtb/IICG/BAAR tecidual, em nenhuma foi obtida positividade na PCR. Contrariamente, a PCR apresentou maior percentual de co-negatividade nas amostras de gânglios do que nas cutâneas, inclusive apresentando VPPs bastante elevados nos gânglios, atingindo $100 \%$ (4/4) quando analisada com os métodos de cultivo Mtb/IICG/BAAR tecidual.

Visto que a PCR ainda é um método diagnóstico em estudo e que a presença de IICG quase sempre induz uma suspeita de tuberculose quando outros agentes etiológicos não são detectados, realizou-se a análise dos resultados obtidos entre o IICG e o cultivo, tendo o cultivo como padrão-ouro. Os dados obtidos estão apresentados na Tabela 3. Mediante os resultados, constatou-se que, na amostragem estudada, a presença de IICG no gânglio é mais indicativa de $\mathrm{Tb}$ do que em amostras cutâneas e que em ambos os tipos de amostra é possível o diagnóstico de Tb sem a presença de IICG.

\section{Discussão}

A ausência de interferência na PCR pelo tempo de emblocamento é contrária ao disposto por alguns autores ${ }^{(9,29)}$. No presente estudo, a não-interferência pode ser devida ao uso de oligonucleotídeos com amplificação de segmentos inferiores a $200 \mathrm{pb}$ na principal etapa da PCR, conforme resultados e recomendações de Greer et al. ${ }^{(9)}$.

A falsa-positividade da PCR como diagnóstico de tuberculose nas oito amostras cutâneas, cujos cultivos foram positivos para MNT, pode ser devida a impedimento de isolamento do $M$. tuberculosis resultante do desenvolvimento exuberante e mais rápido das MNTs presentes na amostra clínica; a colonização da derme ou oportunismo

Tabela 1

Resultados da PCR em relação ao infiltrado inflamatório crônico granulomatoso e ao cultivo

\begin{tabular}{|c|c|c|c|c|c|c|c|c|c|c|}
\hline \multirow{3}{*}{\multicolumn{2}{|c|}{ Tipos de amostra e PCR }} & \multirow{2}{*}{\multicolumn{3}{|c|}{$\begin{array}{l}\text { IICG com BAAR } \\
\text { Cultivo para Mtb }\end{array}$}} & \multirow{2}{*}{\multicolumn{3}{|c|}{$\begin{array}{l}\text { IICG sem BAAR } \\
\text { Cultivo para Mtb }\end{array}$}} & \multirow{2}{*}{\multicolumn{3}{|c|}{$\begin{array}{l}\text { Sem IICG e sem BAAR } \\
\text { Cultivo para Mtb }\end{array}$}} \\
\hline & & & & & & & & & & \\
\hline & & Pos & Neg & Total & Pos & Neg & Total & Pos & Neg & Total \\
\hline \multirow{3}{*}{ Pele PCR } & Pos & 0 & 9 & 9 & 2 & 11 & 13 & 2 & 7 & 9 \\
\hline & $\mathrm{Neg}$ & 1 & 4 & 5 & 1 & 9 & 10 & 1 & 5 & 6 \\
\hline & Totais & 1 & 13 & 14 & 3 & 20 & 23 & 3 & 12 & 15 \\
\hline Co-positividade & & \multicolumn{3}{|c|}{$0 \%$} & \multicolumn{3}{|c|}{$66,7 \%$} & \multicolumn{3}{|c|}{$66,7 \%$} \\
\hline Co-negatividade & & \multicolumn{3}{|c|}{30,8} & \multicolumn{3}{|c|}{$45 \%$} & \multicolumn{3}{|c|}{$41,7 \%$} \\
\hline VPP & & \multicolumn{3}{|c|}{$0 \%$} & \multicolumn{3}{|c|}{$15,4 \%$} & \multicolumn{3}{|c|}{$22,2 \%$} \\
\hline VPN & & \multicolumn{3}{|c|}{$80 \%$} & \multicolumn{3}{|c|}{$90 \%$} & \multicolumn{3}{|c|}{$83,3 \%$} \\
\hline \multirow{3}{*}{ Gânglio PCR } & Pos & 4 & 0 & 4 & 4 & 1 & 5 & 1 & 1 & 2 \\
\hline & Neg & 8 & 1 & 9 & 2 & 5 & 7 & 2 & 2 & 4 \\
\hline & Totais & 12 & 1 & 13 & 6 & 6 & 12 & 3 & 3 & 6 \\
\hline Co-positividade & & \multicolumn{3}{|c|}{$33,3 \%$} & \multicolumn{3}{|c|}{$66,7 \%$} & \multicolumn{3}{|c|}{$33,3 \%$} \\
\hline Co-negatividade & & \multicolumn{3}{|c|}{$100 \%$} & \multicolumn{3}{|c|}{$83,3 \%$} & \multicolumn{3}{|c|}{$66,7 \%$} \\
\hline VPP & & \multicolumn{3}{|c|}{$100 \%$} & \multicolumn{3}{|c|}{$80 \%$} & \multicolumn{3}{|c|}{$50 \%$} \\
\hline VPN & & \multicolumn{3}{|c|}{$11,1 \%$} & \multicolumn{3}{|c|}{$71,4 \%$} & \multicolumn{3}{|c|}{$50 \%$} \\
\hline
\end{tabular}

IICG = infiltrado inflamatório crônico granulomatoso; BAAR = bacilo álcool-ácido-resistente; Mtb = Mycobacterium tuberculosis; Pos = positivo; Neg = negativo. 


\begin{tabular}{|c|c|c|c|c|c|c|}
\hline & \multicolumn{6}{|c|}{$\begin{array}{l}\text { Resultados de acurácia entre a PCR e os métodos laboratoriais diagnósticos de tuberculose } \\
\text { cutânea e/ou ganglionar, conforme a origem da amostra clínica }\end{array}$} \\
\hline & PCR & Cultivo Mtb & $\begin{array}{l}\text { Cultivo Mtb/ } \\
\text { IICG }\end{array}$ & $\begin{array}{l}\text { Cultivo Mtb/IICG/ } \\
\text { BAAR tecidual }\end{array}$ & $\begin{array}{l}\text { IICG/BAAR } \\
\text { tecidual }\end{array}$ & IICG \\
\hline \multirow[t]{2}{*}{ Co-pos } & Pele & $57,1 \%(4 / 7)$ & $50 \%(2 / 4)$ & $0 \%(0 / 1)$ & $69,2 \%(9 / 13)$ & $59,5 \%(22 / 37)$ \\
\hline & Gânglio & $42,9 \%(9 / 21)$ & $44,4 \%(8 / 18)$ & $33,3 \%(4 / 12)$ & $30,8 \%(4 / 13)$ & $36,0 \%(9 / 25)$ \\
\hline \multirow[t]{2}{*}{ Co-neg } & Pele & $40 \%(18 / 45)$ & $41,7 \%(5 / 12)$ & $30,7 \%(4 / 13)$ & $40 \%(6 / 15)$ & $40 \%(6 / 15)$ \\
\hline & Gânglio & $80 \%(8 / 10)$ & $66,7 \%(2 / 3)$ & $100 \%(1 / 1)$ & $66,7 \%(4 / 6)$ & $66,7 \%(4 / 6)$ \\
\hline \multirow[t]{2}{*}{ VPP } & Pele & $12,9 \%(4 / 31)$ & $22,2 \%(2 / 9)$ & $0 \%(0 / 9)$ & $50 \%(9 / 18)$ & $71 \%(22 / 31)$ \\
\hline & Gânglio & $81,8 \%(9 / 11)$ & $89 \%(8 / 9)$ & $100 \%(4 / 4)$ & $66,7 \%(4 / 6)$ & $81,8 \%(9 / 11)$ \\
\hline \multirow[t]{2}{*}{ VPN } & Pele & $85,7 \%(18 / 21)$ & $71,4 \%(5 / 7)$ & $80 \%(4 / 5)$ & $60 \%(6 / 10)$ & $28,6 \%(6 / 21)$ \\
\hline & Gânglio & $40 \%(8 / 20)$ & $16,7 \%(2 / 12)$ & $11,1 \%(1 / 9)$ & $30,8 \%(4 / 13)$ & $20 \%(4 / 20)$ \\
\hline
\end{tabular}

Mtb = Mycobacterium tuberculosis; IICG = infiltrado inflamatório crônico granulomatoso; BAAR = bacilo álcool-ácido-resistente; co-pos = co-positividade; co-neg = co-negatividade; $V P P=$ valor preditivo positivo; VPN = valor preditivo negativo.

Tabela 3

Resultados de acurácia entre a presença ou a ausência de infiltrado inflamatório crônico granulomatoso e o cultivo para Mycobacterium tuberculosis, tendo o cultivo como padräo-ouro

\begin{tabular}{|c|c|c|c|c|}
\hline \multirow{2}{*}{\multicolumn{2}{|c|}{ Tipos de amostra e IICG }} & Cultivo M. tuberculosis & Cultivo M. tuberculosis & \\
\hline & & Pos & Neg & Total \\
\hline \multirow{3}{*}{ Pele } & Com IICG & $4(7,7 \%)$ & $33(63,5 \%)$ & $37(71,2 \%)$ \\
\hline & Sem IICG & $3(5,8 \%)$ & $12(23 \%)$ & $15(28,8 \%)$ \\
\hline & Total & $7(13,5 \%)$ & $45(86,5 \%)$ & $52(100 \%)$ \\
\hline \multicolumn{2}{|c|}{ Co-positividade } & & & $57,1 \%(4 / 7)$ \\
\hline \multicolumn{2}{|c|}{ Co-negatividade } & & & $26,7 \%(12 / 45)$ \\
\hline \multicolumn{2}{|l|}{ VPP } & & & $10,8 \%(4 / 37)$ \\
\hline \multicolumn{2}{|l|}{ VPN } & & & $80 \%(12 / 15)$ \\
\hline \multirow{3}{*}{ Gânglio } & Com IICG & $18(58,0 \%)$ & $7(22,6 \%)$ & $25(80,6 \%)$ \\
\hline & Sem IICG & $3(9,7 \%)$ & $3(9,7 \%)$ & $6(19,4 \%)$ \\
\hline & Total & $21(67,7 \%)$ & $10(32,3 \%)$ & $31(100 \%)$ \\
\hline \multicolumn{2}{|c|}{ Co-positividade } & & & $85,7 \%(18 / 21)$ \\
\hline \multicolumn{2}{|c|}{ Co-negatividade } & & & $30 \%(3 / 10)$ \\
\hline \multicolumn{2}{|l|}{ VPP } & & & $72 \%(18 / 25)$ \\
\hline \multicolumn{2}{|l|}{ VPN } & & & $50 \%(3 / 6)$ \\
\hline
\end{tabular}

IICG = infiltrado inflamatório crônico granulomatoso; pos = positivo; neg = negativo; VPP = valor preditivo positivo; VPN = valor preditivo negativo.

e colonização da lesão cutânea, visto que existe o relato da presença de várias espécies de micobactérias na flora da pele normal de pessoas residentes no estado do Amazonas $^{(19,20)}$; a existência, na Amazônia, de espécies de MNT contendo a IS6110, conforme também relatado por Santos et al. ${ }^{(18)}$; ou a uma homologia entre o DNA destas
MNTs e a IS6110, semelhante ao exposto por outros autores ${ }^{(3,11,15)}$. Visto que em quatro amostras o problema parece estar relacionado com o impedimento de desenvolvimento do $M$. tuberculosis, a falsa-positividade foi de 9,5\% para todos os casos. Entretanto, como só ocorreu nas amostras cutâneas, tem-se uma elevação para 12,9\% 
de falsa-positividade. Vale ressaltar que Marchetti et al.(14) não detectaram nenhum caso de falsa-positividade pelo protocolo PCR4. Além disso, é importante enfatizar que a contaminação cruzada de DNA foi excluída como hipótese de PCR falso-positivo. Tal fato é devido ao uso de materiais descartáveis em todas as etapas dos procedimentos e à negatividade da PCR em todos os controles negativos de extração de DNA das amostras teciduais, inclusive os de microtomia, parafina e reagentes.

É possível que no presente estudo a baixa positividade de $50,6 \%(42 / 83)$ ou de $45,8 \%$ da PCR (38/83 após a exclusão dos resultados falso-positivos) em relação à média de $80 \%$ encontrada por Marchetti et al.(14) seja devida à não-padronização da concentração de DNA, conforme recomendado pelos autores para o protocolo PCR4. Essa premissa encontra respaldo quando se analisam os resultados da PCR, conforme a amostra clínica, a presença de BAAR tecidual com cultivo negativo ou não para o $M$. tuberculosis (Tabela 1). Nas lesões cutâneas, geralmente paucibacilares ${ }^{(23)}$, a negatividade da PCR foi de $35,7 \%$, enquanto que nas ganglionares, em que um número maior de bacilos é encontrado, foi de 69,2\%. Marchetti et al.(14) também encontraram falsa-negatividade em gânglios (25\%). Os resultados do cultivo induzem ainda mais esse fato, pois, nas amostras cutâneas, a positividade para M. tuberculosis foi de $7,1 \%$, enquanto nas ganglionares, $92,3 \%$. Conseqüentemente, tem-se a premissa de que a não-padronização da concentração do DNA pode ser responsável pela baixa positividade da PCR, principalmente nas amostras ganglionares.

A crescente ampliação do VPP da PCR nas amostras cutâneas (Tabela 1), conforme a exclusão dos parâmetros indicativos de Tb (IICG e BAAR), pode ser devida aos também crescentes percentuais de isolamento de MNT, conforme exposto no tópico "Resultados". É possível que os elevados percentuais de co-negatividade e de VPP da PCR em relação ao cultivo $M$ tb, nas amostras ganglionares (Tabela 2), sejam devidos ao fato de que essas lesões não possuem a presença de micobactérias existentes na microbiota cutânea normal| ${ }^{(19,20)}$.

Com respaldo nos idênticos VPPs da PCR (Tabela 2), quando relacionada com o cultivo ou com o exame histopatológico, pode-se inferir que na rotina diagnóstica ela possa ser utilizada concomitantemente com um ou outro método na definição do diagnóstico de Tb. Entretanto, por ser o cultivo um exame mais demorado, a opção de utilizar-se a PCR com o histopatológico diminuiria o tempo de decisão diagnóstica.
Numa análise apenas dos métodos tradicionais - cultivo e histopatológico - a literatura já demonstra que o isolamento do agente etiológico de tecidos cutâneos não é rotineiramente realizado ${ }^{(10,13,14,16)}$ devido à baixa positividade do método ${ }^{(17)}$, semelhante ao que ocorreu no presente estudo (Tabela 3). Essa dificuldade, aliada ao fato de que diferentes autores indicam a presença de granulomas como achado classicamente relacionado à $\mathrm{Tb}^{(12,23,24)}$, induz, na prática clínica, uma valorização dessa alteração histopatológica como parâmetro de diagnóstico definitivo. No presente trabalho, este também foi o achado laboratorial mais freqüentemente relacionado com a suspeita de infecção tuberculosa, principalmente em lesões ganglionares (Tabela 3). Entretanto, a confirmação do diagnóstico de TbCG pelo cultivo também foi possível na ausência de granulomas, fato respaldado na possibilidade das lesões micobacterianas apresentarem-se histologicamente de forma espectral(23) e na distribuição espacial dos BAAR na lesão(8).

\section{Conclusão}

Pelo conjunto dos dados apresentados constatou-se que o protocolo PCR4 de Marchetti et al. ${ }^{(14)} \mathrm{em}$ tecidos parafinizados de casos suspeitos de TbCG apresentou positividade em percentual semelhante a diferentes protocolos existentes na literatura e não-suficientes para elucidação diagnóstica.

Os resultados obtidos permitem sugerir o uso da PCR associado com o cultivo ou o exame histopatológico para o diagnóstico definitivo de Tb ganglionar. Nessa forma da doença, a PCR pode ser realizada a partir dos tecidos parafinizados, propiciando agilidade na confirmação da suspeita diagnóstica. Contudo, para as lesões cutâneas continua sendo necessária a busca de protocolo que amplie a acurácia do método, principalmente para uso em regiões onde, na microbiota normal humana, são encontradas com freqüência as micobactérias ambientais (micobactérias não-tuberculosas), como é o caso do estado do Amazonas.

\section{Agradecimentos}

Aos serviços de Patologia da Fundação Alfredo da Matta, do Instituto de Medicina Tropical de Manaus e da UFAM. A Mari O. Lima, Francisco F. Carvalho e Raimundo B. Nascimento, técnicos do Laboratório de Micobacteriologia do INPA; a Maria de Fátima Barbosa, técnica de histopatologia da UFAM; a Luciana Freire de Oliveira, acadêmica de Medicina da UFAM. 


\section{Referências}

I. BASELGA, E. et al. Detection of Mycobacterium tuberculosis DNA in lobular granulomatous panniculitis (erythema induratum - nodular vasculitis). Arch Dermatology, v. I33, p. 457-62, 1997.

2. BEHMER, O. A.; TOLOSA, E. M.C; NETO, A. G. F. Manual de técnicas para histologia normal e patológica. São Paulo: Editora da Universidade de São Paulo, 1976. p. 80-180.

3. BHANU, N.V. et al. Two Mycobacterium tuberculosis strains isolated from pulmonary tuberculosis patients in Delhi harbour IS6 110 homologue. Diag Microbiol and Infectious Disease, v. 48, p. I0710,2004 .

4. CDC - CENTER OF DISEASE CONTROL. EPIINFO, Versão 6.04d, para DOS produzido e distribuído gratuitamente pelo Centro de Controle de Doenças - CDC. Califórnia, 1997.

5. CHEN,Y. et al. Erythema induratum: a clinicopathologic and polymerase chain reaction study. J Formos Medical Association, v. 100, n. 4, p. 244-9, 2001.

6. DAVID, L. H.; LÉVI-FRÉBAULT, V.; THOREL, M. F. Mèthode de laboratoire pour mycobacteriologie clinique. Paris: Institut Pasteur, 1989.87p.

7. EISENACH, K. D. et al. Polymerase chain reaction amplification of a repetitive DNA sequence specific for Mycobacterium tuberculosis. J Infec Dis, v. 161, p. 977-81, 1990.

8. FENHALLS et al. Localization of mycobacterial DNA and mRNA in human tuberculous granulomas. J Microbiol Meth, v. 5I, p. 197-208, 2002

9. GREER, C. E.;WHEELER, C. M.; MANOS, M. PCR amplification from paraffin-embedded tissues: sample preparation and the effects of fixation. In: DIEFFENBACH, C. W:; DVEKSLER, G. S. (eds.). PCR primer.a laboratory manual. Cold Spring Harbor Laboratory Press, 1995. p. 99-112.

10. HSIAO, P. F. et al. Polymerase chain reaction based detection of Mycobacterium tuberculosis in tissues showing granulomatous inflammation without demonstrable acid-fast bacilli. Int J Dermatol, v. 42, p. 28I-6, 2003 .

I I. KENT, L et al. Demonstration of homology between IS6 I I0 of Mycobacterium tuberculosis and DNAs of Other Mycobacterium spp.J Clin Microbiol, v. 33, n. 9, p. 2290-3, 1995.

12. KUMAR, V:; ABBAS, A. K.; FAUSTO, N. (eds.). Robbins e Contran patologia: bases patológicas das doenças. Rio de Janeiro: Elsevier Editora Ltda, 2005.

13. LI, J. Y. W.; LO, S. T. H.; NG, C. S. Molecular detection of Mycobacterium tuberculosis in tissues showing granulomatous inflammation without demonstrable acid-fast bacilli. Diagn Mol Pathol, v. 9, n. 2, p. 67-74, 2000.

14. MARCHETTI, G. et al. Evaluation of PCR in detection of Mycobacterium tuberculosis from formalin-fixed, paraffinembedded tissue: comparison of four amplification assays. J Clin Microbiol, v. 36, n. 6, p. 15।2-7, 1998.

I5. McHUGH,T. D; NEWPORT, L. E; GILLESPIE, S.H. IS6 1 I 0 homologs are present in multiple copies in mycobacteria other than tuberculosis-causing mycobacteria. J Clin Microbiol, v. 35, n. 7, p. |769-7|, 1997.
16. PARK, D. Y.; KIM, J. Y.; KYUNG, U. C. Et al. Comparasion of polymerase chain reaction with histopathologic features for diagnosis of tuberculosis in formalin-fixed, paraffinembedded histologic specimens. Arch Pathol Lab Med, v. 127, p. 326-30, 2003.

17. PFLALLER, M. A. Application of new technology to the detection, identification and antimicrobial susceptibility testing by mycobacteria. Clin Microbiol Inf Dis, v. I0I, p. 329-37, 1994

18. SANTOS, R. M. C.; OGUSKU, M. M.; MIRANDA, J. M. et al. Avaliação da PCR no diagnóstico da tuberculose pulmonar em pacientes indígenas e não-indígenas. J Bras Pneumol, v. 32, n. 3, p. 234-40, 2006.

19. SALEM, J. I. Presença de micobactérias na pele e sua importância em lesões cutâneas. Tese (Doutorado em Ciências - Microbiologia) - Instituto de Microbiologia, Universidade Federal do Rio de Janeiro, Rio de Janeiro, 1987.

20. SALEM, J.I.; GONTIJO-FILHO, P.; LEVY-FREBAULT, V. et al. Isolation and characterization of mycobacteria colonizing the healthy skin. Acta Leprologica, v. 7, supl. I, p. 18-20, 1989a.

2I. SALEM, J. I., GADELHA, A. R.; MAROJA, F. et al. Non-cultivable mycobacteria in ulcers of the skin. Acta Leprologica, v. 7, supl. I, p. 10-5, 1989b.

22. SALIAN et al. Polymerase chain reaction to detect Mycobacterium tuberculosis in Histologic Specimens. Am J Respir Crit Care Med, v. I58, n. 4, p. II50-5, 1998.

23. SANTA CRUZ, D. J.; STRAYER, D. S. The histologic spectrum of the cutaneous mycobacterioses. Hum Path, 13: 485-95, 1982.

24. SEHGAL, S. H.; WAGH, S. A. The history of cutaneous tuberculosis. Int / Dermatol, v. 29, n. 9, p. 666-8, 1990.

25. SENTURK, N.; SAHIN, S.; KOCAGOZ, T. Polymerase chain reaction in cutaneous tuberculosis: is it a reliable diagnostic method in paraffin-embedded tissues? Int J Dermatol, v. 4I, p. 863-6, 2002.

26. SES/AM - GOVERNO DO ESTADO DO AMAZONAS/ SUPERINTENDÊNCIA ESTADUAL DE SAÚDE. C.R.E.P.S.Cardoso Fontes. Relatório de Avaliação Anual do Programa de Controle do Amazonas. Manaus: PCT/SUSAM - Série Histórica de TB, 2002.

27. TAN, S. H.; TAN; B. H.; GOH, C. L. et al. Detection of Mycobacterium tuberculosis DNA using polymerase chain reaction in cutaneous tuberculosis and tuberculids. Int J Dermatol, v. 38, p. 122-7, 1999.

28. WADE, H.W. Demonstration of acid-fast bacilli in tissue sections. Am J Pathol, v. 28, n. I, p. I57-70, 1952.

29. YAMAKAWA, D. B. Deteç̧ão de Mycobacterium tuberculosis pela técnica de polimerase em cadeia em amostras fixadas em formalina e incluídas em parafina. 72p. Dissertação (Mestrado em Ciências Médicas) - Universidade Federal de São Paulo, São Paulo, 2003.

Endereço para correspondência

Luciana Botinelly Mendonça Fujimoto Faculdade de Ciências da Saúde da UFAM Departamento de Patologia e Medicina Legal Rua Apurinã, 1.053 - Praça 14 CEP 69025-050 - Manaus-AM Tels.: (92) 36441947/(92)9981-4649 Fax: (92) 3639-4864 e-mail: olfujimoto@vivax.com.br 